\title{
Synthesis of Graphenes with Arc-Discharge Method
}

\author{
Nan Li, Zhiyong Wang and Zujin Shi \\ College of Chemistry and Molecular Engineering, Peking University \\ People's Republic of China
}

\section{Introduction}

Carbon is one of the elements which form life. It plays a key function in nature and is very crucial for human beings. Carbon has many different kinds of allotropes, some known for thousands of years (graphite and diamond) and some known for several decades (fullerenes and nanotubes). The amazing two-dimensional form, which named graphene, is generated only several years ago. Graphene has raised a new tidal wave of research among the whole globe since its discovery and become a dazzling star in nanoscience.

Graphene is one-atom-thick layer of $\mathrm{sp}^{2}$-hybridized carbon tightly packed into a honeycomb lattice, and is a basic building unit for graphitic materials of all other dimensionalities (Geim et al., 2007). Over the past several years, a great deal of intensive research has been generated by graphene due to its unique electrical, thermal, mechanical, optical and other characteristics(Du et al., 2008; Booth et al., 2008). With the understanding of their physical properties, the promises for application are growing in areas of nanoelectronics, sensors, composites, batteries and hydrogen storage ( $\mathrm{Li}$ et al., 2008).

Nevertheless, the large-scale production of high quality graphene is the principal question, which concerned with the graphene's successful applications. The methods for synthesis of graphene include exfoliation of graphite(Novolesov et al., 2004; Niyogi et al., 2006; Li et al., 2008), chemical vapor deposition(Chae et al., 2009; Yuan et al., 2009; Li et al., 2009; Dervishi et al., 2009), epitaxial growth on electrically insulating surfaces such as SiC(Emtsev et al., 2009; Juang et al., 2009), chemical reduction of graphite oxide and graphite intercalation compounds(McAllister et al., 2007; Fan et al., 2008; Zhu et al., 2010), arc-discharge method(Subrahmanyam et al., 2009; Li et al., 2010a; Wang et al., 2010), other chemical methods(Choucair et al., 2009) and so on. Among the above methods, the arc-discharge method has its unique advantages: no metal catalyst is used; the process is timesaving and facile; high quality graphene could be synthesized in decagram-scale in low cost. In the following section, we will introduce the massive synthesis of graphene through arc-discharge method, including experimental details, characterization and formation mechanisms.

\section{Synthesis of graphene with arc-discharge method}

\subsection{Experimental details}

Arc-discharge method was first used by Krastchmer and Hoffman to synthesize $\mathrm{C}_{60}$ (Krätschmer et al., 1990). In the last two decades, it was widely used to prepare carbon- 
based nanomaterials( $\mathrm{Li}$ et al., 2010a; $\mathrm{Xu}$ et al., 2004; $\mathrm{Xu}$ et al., 2005; Li et al., 2010b). The electric arc oven for synthesis of graphene mainly comprises two electrodes and a steel chamber cooled by water. The cathode and anode are both pure graphite rods. The current in the discharge process is maintained at 100-150 A. Up to now, the atmospheres for arc evaporation of graphite rods are $\mathrm{H}_{2}, \mathrm{NH}_{3}$ and $\mathrm{He}$, air. As the rods are brought close together, discharge occurs resulting in the formation of plasma. As the anode is consumed, the rods are kept at a constant distant from each other of about 1-2 mm by rotating the cathode. When the discharge ends, the soot generated is collected under ambient conditions. Only the soot deposited on the inner wall of the chamber is collected, avoiding the substance at the bottom of the chamber, for the latter tends to contain other graphitic particles. The arc-discharge method is useful to prepare pure, $\mathrm{B}$ - and $\mathrm{N}$-doped graphene. $\mathrm{B}$ doped graphene is obtained by carrying out the discharge in the presence of a mixture of a $\mathrm{H}_{2}$ and $\mathrm{B}_{2} \mathrm{H}_{6}$ (Subrahmanyam et al., 2009). $\mathrm{N}$-doped graphene is obtained by carrying out the discharge in the mixing atmosphere of $\mathrm{He}$ and $\mathrm{NH}_{3}\left(\mathrm{Li}\right.$ et al., 2010a) or $\mathrm{H}_{2}$ and pyridine(Subrahmanyam et al., 2009).

\subsection{Characterizations of graphene}

The graphene can be synthesized in three different kinds of atmospheres with arc-discharge method. We will introduce the characterizations of graphene according to the different atmosphere.

\subsubsection{Graphene synthesized in the atmosphere of $\mathrm{H}_{2}$}

Subrahmanyam et al.( 2009) first synthesized pure graphene(HG) with the arc-discharge method in the atmosphere of $\mathrm{H}_{2}$. They also synthesized $\mathrm{B}-(\mathrm{BG})$ and $\mathrm{N}$-doped graphene (NG) in the presence of $\mathrm{B}_{2} \mathrm{H}_{6}$ and pyridine. Fig. 2.1 is the transmission electron microscopy (TEM) images of the graphene. TEM image of HG shown in Fig. 2.1a reveals the presence of 2-4 layers. Fig. 2.2 shows typical atomic force microscopy (AFM) images with the height profiles. AFM images show the thickness to be generally around $0.7-1 \mathrm{~nm}$ corresponding to 2-3 layers, consistent with the TEM results.

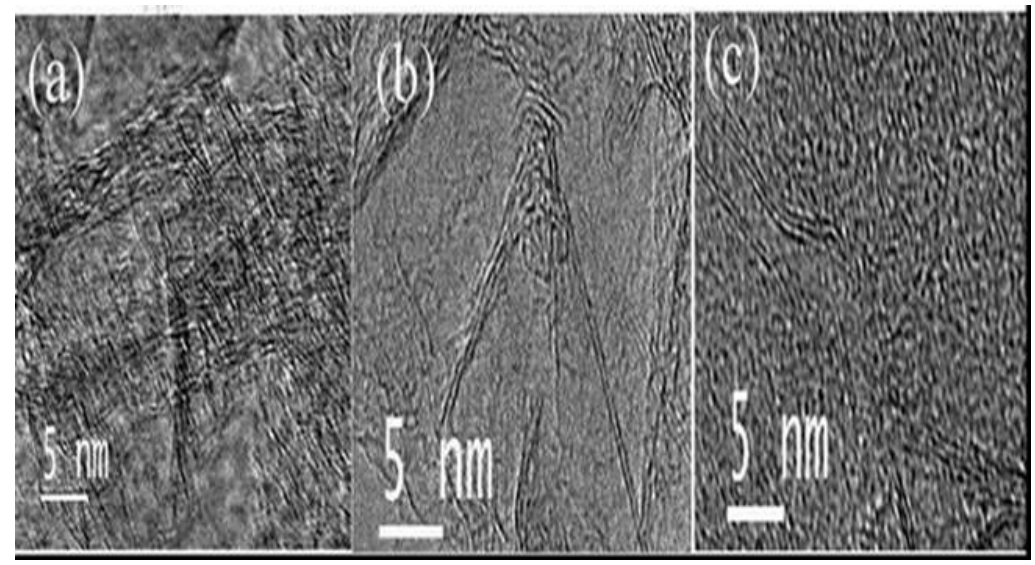

Fig. 2.1. TEM images of (a) HG and (b) BG and (c) NG graphenes. (Subrahmanyam et al. 2010. Reproduced by permission of The American Chemistry Society) 

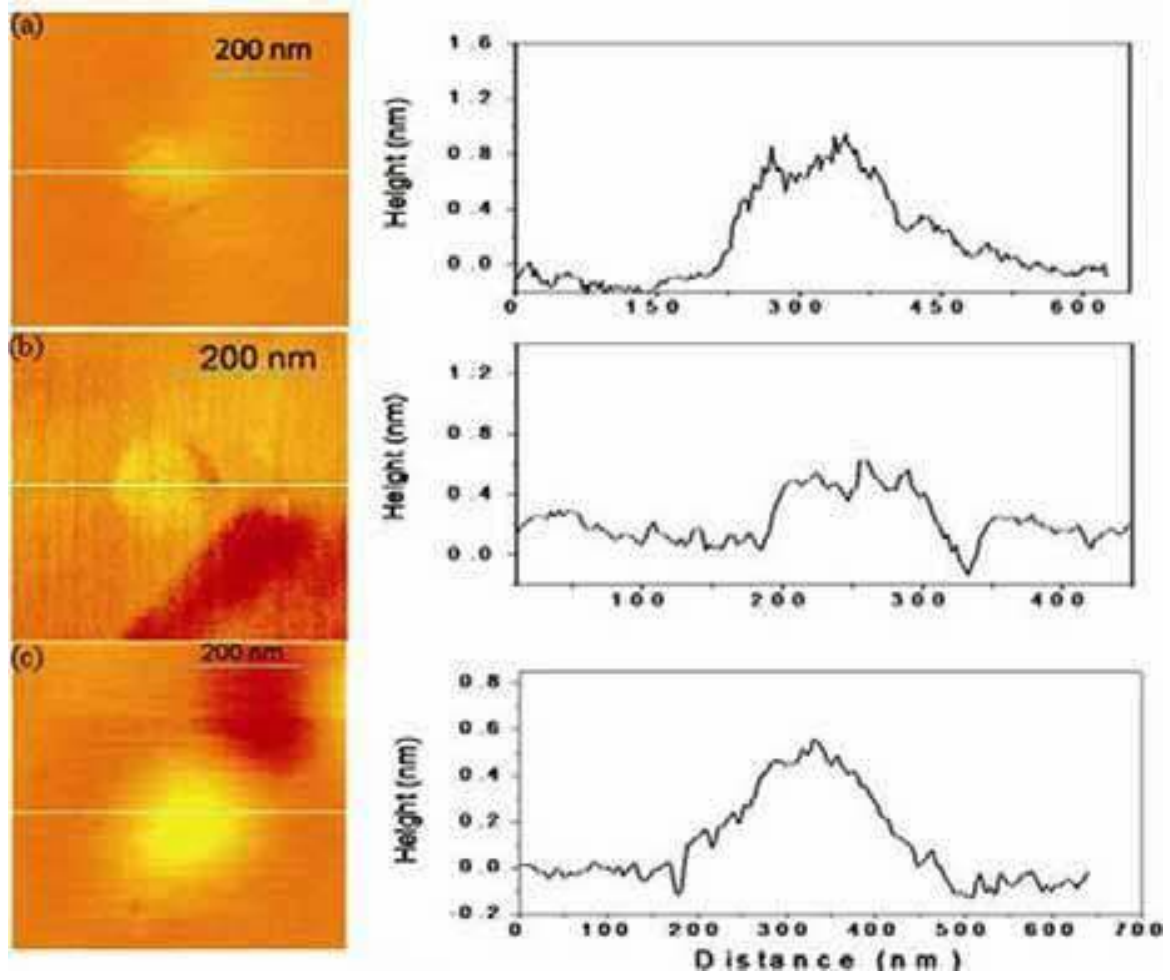

Fig. 2.2. Noncontact mode AFM images of (a, b) HG and (c) BG graphenes with height profiles. (Subrahmanyam et al. 2010. Reproduced by permission of The American Chemistry Society)

Fig. 2.3 shows the Raman spectra of HG, BG, and NG. The Raman spectrum of HG exhibits the characteristic D, G, and the 2D bands of graphene around 1323, 1569, and $2634 \mathrm{~cm}^{-1}$ respectively. It also shows the defect related G' band as a shoulder around $1600 \mathrm{~cm}^{-1}$. Raman spectra of BG and NG show a blue-shifted G band (1576 and $1572 \mathrm{~cm}^{-1}$ in BG and NG, respectively) compared to $\mathrm{HG}\left(1569 \mathrm{~cm}^{-1}\right)$. BG and $\mathrm{NG}$ show a more intense $\mathrm{D}$ band and a less intense $2 \mathrm{D}$ band relative to $\mathrm{HG}$. The area of the HG samples is generally in the range of $10-40 \times 10^{3} \mathrm{~nm}^{2}$. The surface areas of the HG samples, determined by the Brunauer-EmmettTeller (BET) method are in the range of $270-680 \mathrm{~m}^{2} / \mathrm{g}$. The synthesis, structure, and properties of BG and NG are being investigated in detail by Subrahmanyam et al.

\subsubsection{Graphene synthesized in the mixing atmosphere of $\mathrm{He}$ and $\mathrm{NH}_{3}$}

$\mathrm{Li}$ et al.( 2010a) synthesized $\mathrm{N}$-doped multi-layered graphene in the mixing atmosphere of $\mathrm{He}$ and $\mathrm{NH}_{3}$. Fig. 2.4 is the TEM image of multi-layered graphene, from which we can see large area of high purity multi-layer graphene with the size of $100 \sim 200 \mathrm{~nm}$. Fig. 2.5a to 2.5c is the high resolution transmission electron microscope (HRTEM) images of multi-layered graphene with layer numbers of 2 4. According to the HRTEM observation, the multilayered graphene are mainly of $2 \sim 6$ layers. Fig. 2.6 is the X-ray diffraction (XRD) pattern of the graphene. It shows broad (002) reflection around $25^{\circ}$ and overlapping (100) and (101) reflections around $45^{\circ}$. 


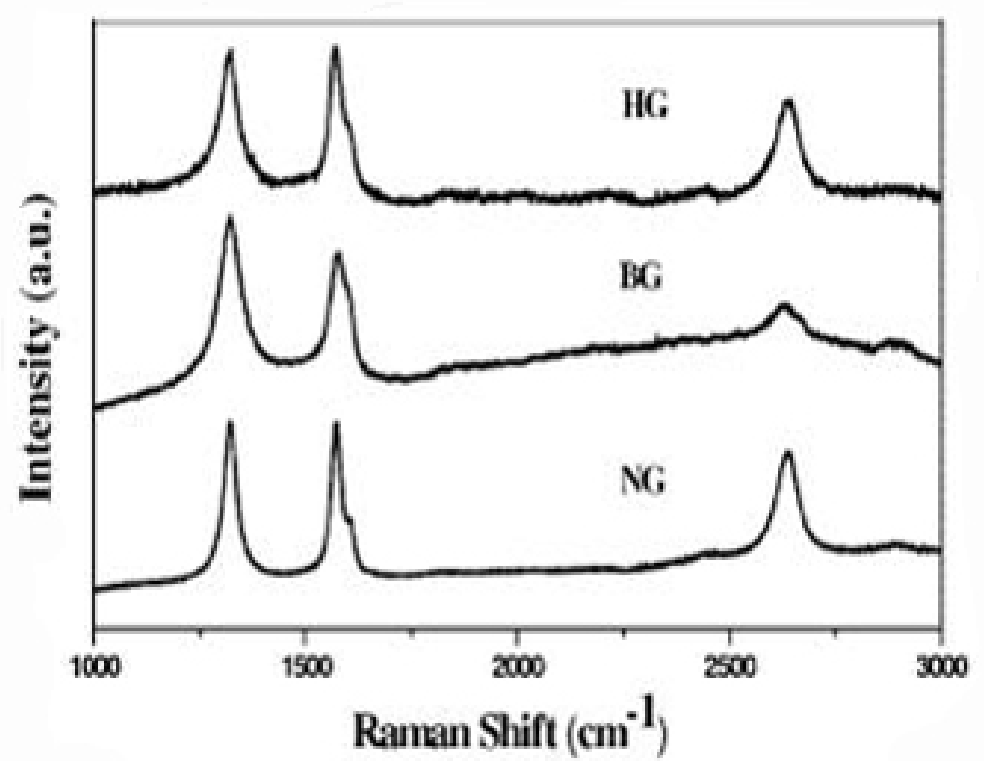

Fig. 2.3. Raman spectra of HG, BG, and NG graphene samples. (Subrahmanyam et al. 2010. Reproduced by permission of The American Chemistry Society)

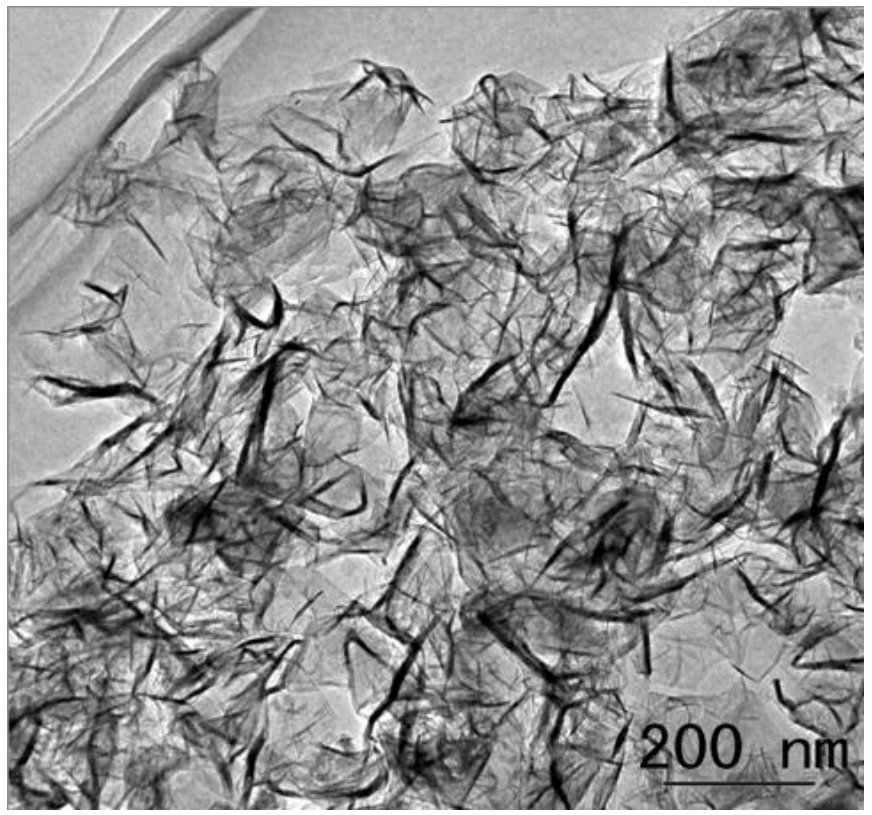

Fig. 2.4. TEM image of multi-layered graphene produced by arc-discharge method. (Li et al. 2010a. Reproduced by permission of Elsevier Limited) 

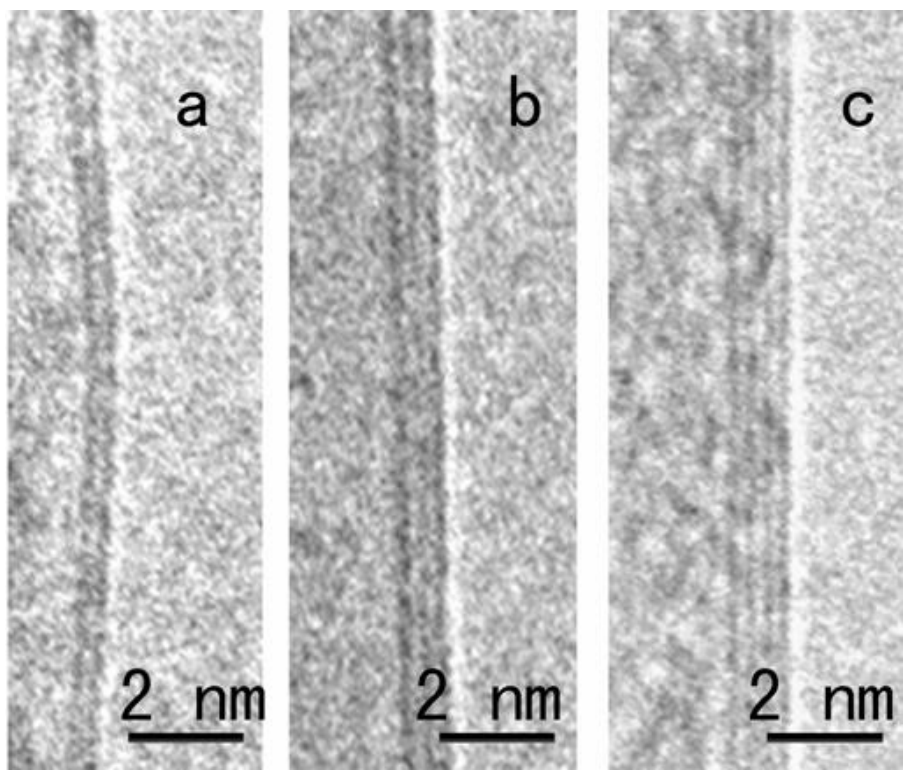

Fig. 2.5. HRTEM images showing the edge of multi-layered graphene consisting of two (a), three (b) and four (c) layers. (Li et al. 2010a. Reproduced by permission of Elsevier Limited)

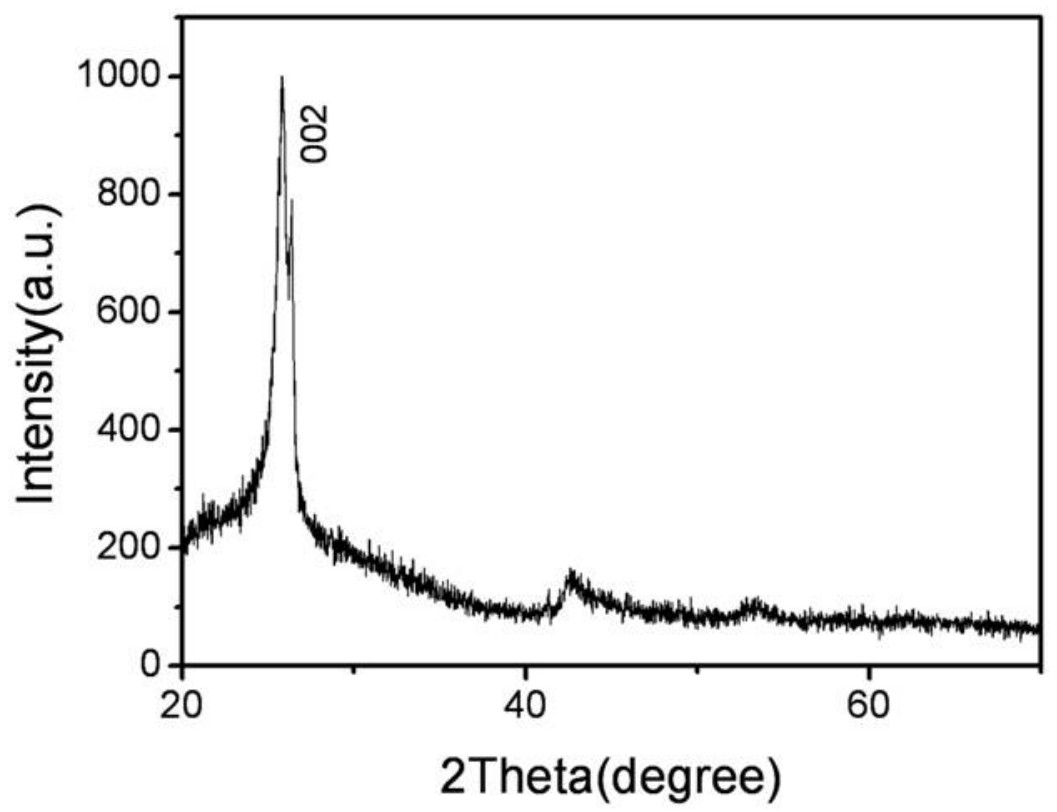

Fig. 2.6. XRD pattern of multi-layered graphene. (Li et al. 2010a. Reproduced by permission of Elsevier Limited) 
Fig. 2.7 shows the Raman spectra of multi-layered graphene. There are three dominant peaks. The two most intense features are the $\mathrm{G}$ band at $\sim 1560 \mathrm{~cm}^{-1}$ and the $2 \mathrm{D}$ band at $\sim 2600$ $\mathrm{cm}^{-1}$. The peak at $\sim 1350 \mathrm{~cm}^{-1}$ is the $\mathrm{D}$ band. The $\mathrm{G}$ band corresponds to the zone center $\mathrm{E}_{2 \mathrm{~g}}$ mode(Ferrari et al. 2006) related to phonon vibrations in $\mathrm{sp}^{2}$ carbon materials(Malesevic et al., 2008). The 2D band has nothing to do with the $\mathrm{G}$ band, but is an overtone of the disorder-induced D band, which is frequently observed in carbon materials(Parvizi et al., 2008). The $D$ band arising from disorder is weak in a single-layer graphene and increases in intensity with the numbers of layers(Submanyam et al., 2008). The $2 \mathrm{D}$ band is also sensitive to the number of layers. The shape of the $\mathrm{D}$ and $2 \mathrm{D}$ band, more specially the absence of a typical graphite shoulder, is a characteristic feature of graphene. The intensity ratio of the D band to the $\mathrm{G}$ band is measured and denoted as the $\mathrm{R}$ value to analysis the structure of graphitic materials(Malesevic et al., 2008; Kastner et al., 1994). The $\mathrm{I}_{\mathrm{G}} / \mathrm{I}_{2 \mathrm{D}}$ is also changed with the layers of graphene(Reina et al., 2009). The $\mathrm{R}$ value is by definition inversely proportional to quality. The $\mathrm{R}$ value is $\sim 0.26$ (Fig. 2.7a) and $\sim 0.23$ (Fig. 2.7b) for the multilayered graphene and the $\mathrm{I}_{\mathrm{G}} / \mathrm{I}_{2 \mathrm{D}}$ is $\sim 1.90$ and $\sim 1.57$. This indicates that the $\mathrm{N}$-doped multilayered graphene produced by arc-discharge method bear well crystalline structure and the number of graphene's layers is not influenced significantly by the content of $\mathrm{NH}_{3}$.

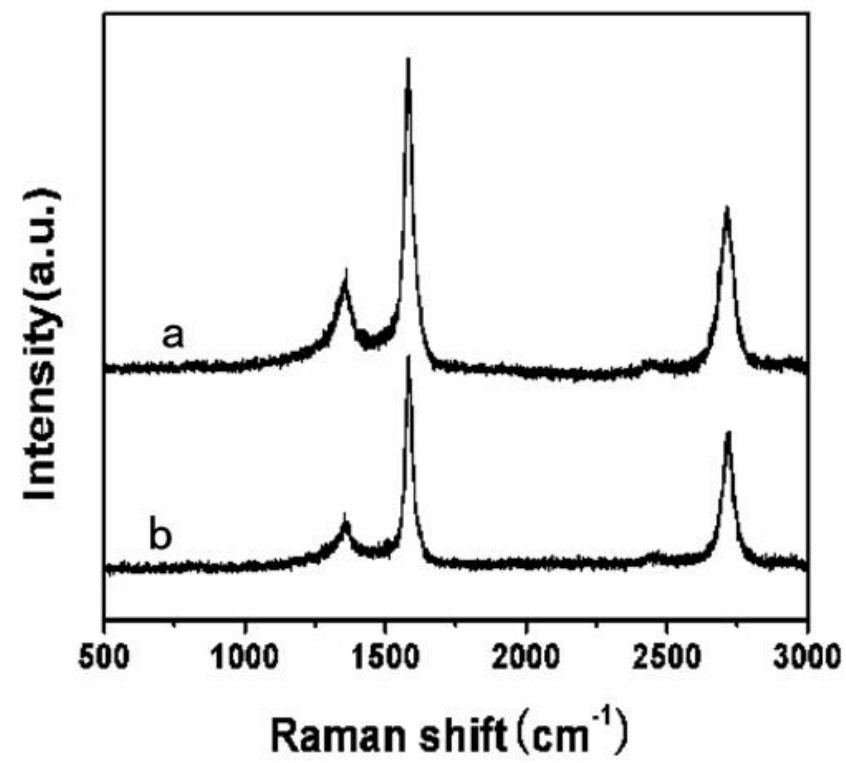

Fig. 2.7. Raman spectra of the two samples prepared in mixing atmosphere of $\mathrm{NH}_{3}$ and $\mathrm{He}$ with the different ratio of $\mathrm{NH}_{3} / \mathrm{He}(\mathrm{V} / \mathrm{V})$ : (a) $\mathrm{NH}_{3}$ : $\mathrm{He}=1: 0$; (b) $\mathrm{NH}_{3}: \mathrm{He}=1: 1$. (Li et al. 2010a. Reproduced by permission of Elsevier Limited)

Fig. 2.8 shows the TGA curve of the $\mathrm{N}$-doped multi-layered graphene. There are two significant drops in mass around 387 and $688^{\circ} \mathrm{C}$. The former is assigned to the oxidation of amorphous carbon, and the latter is attributed to the combustion of the carbon skeleton of graphene sheets. From the TGA curve, we can conclude that the N-doped multi-layered graphene is thermally stable and starts to lose mass upon heating at $500{ }^{\circ} \mathrm{C}$ and the content 
of graphene in raw soot is $\sim 79 \mathrm{wt} . \%$. After the heat treatment at $450{ }^{\circ} \mathrm{C}$ for $1 \mathrm{~h}$ in the atmosphere of air, there was not any amorphous carbon in the soot (Fig. 2.9). From the experimental results we can see that the $\mathrm{N}$-doped multi-layered graphene produced by arcdischarge method can be purified by a simple heat treatment process.

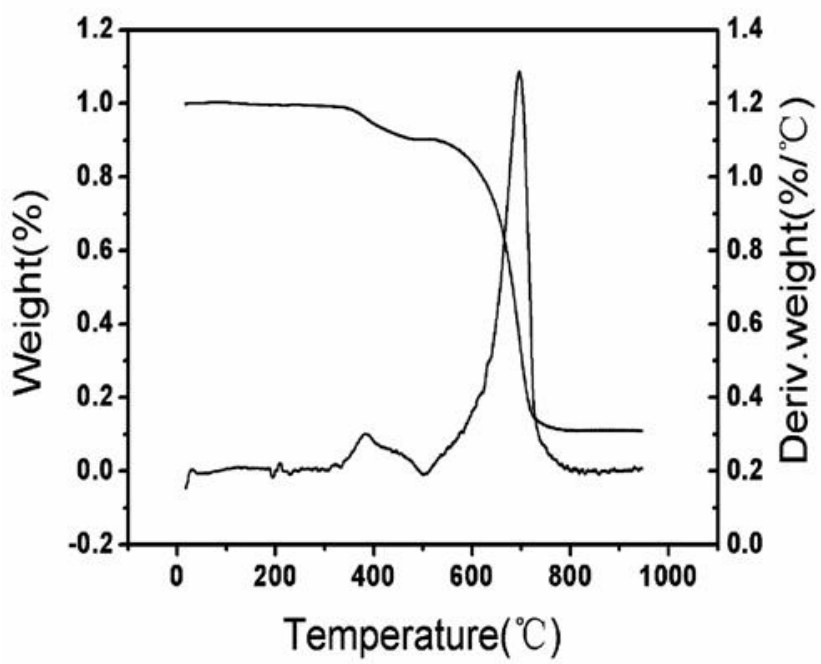

Fig. 2.8. TGA curve of N-doped multi-layered graphene. (Li et al. 2010a. Reproduced by permission of Elsevier Limited)

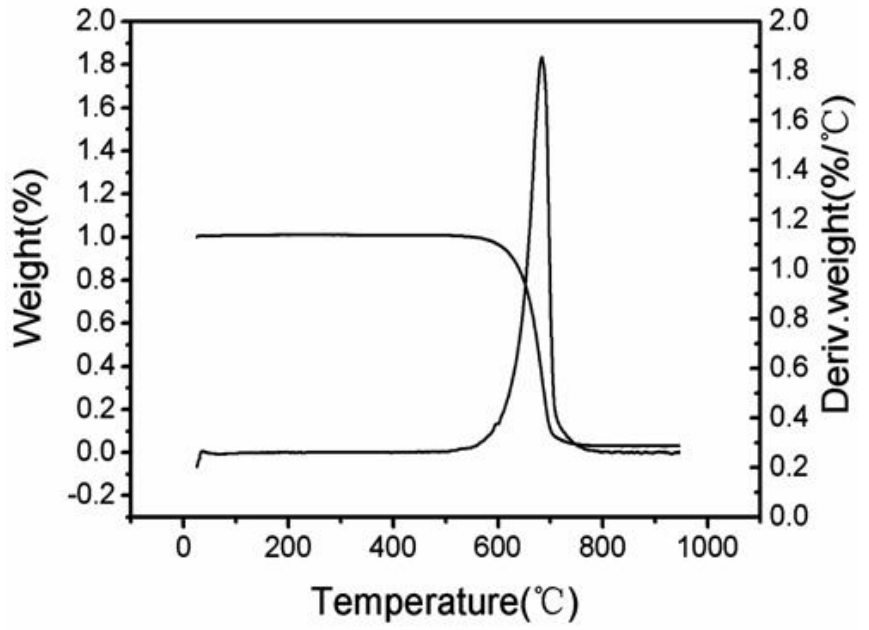

Fig. 2.9. TGA curve of multi-layered graphene sheets after heat treatment at $450{ }^{\circ} \mathrm{C}$ for $1 \mathrm{~h}$. (Li et al. 2010a. Reproduced by permission of Elsevier Limited) 
The XPS results shown in Fig. 2.10 confirm the existence of $\mathrm{N}$. The peaks appeared at 284.50, 399.59 and $532.70 \mathrm{eV}$ can be assigned to $\mathrm{C}_{1 \mathrm{~s}}, \mathrm{~N}_{1 \mathrm{~s}}$ and $\mathrm{O}_{1 \mathrm{~s}}$. No extra peaks except $\mathrm{C}, \mathrm{N}$ and $\mathrm{O}$ were observed, indicating the high purity of the product. Oxygen can be included due to exposure to the air. In graphene sheets, the $\mathrm{C}$ atoms are mostly constrained to a $\mathrm{sp}^{2}-$ hybridization. There are two types of $\mathrm{N}$ bonding for $\mathrm{N}$-doped graphene(Ayala et al., 2001). One is substitutional doping, which $\mathrm{N}$ is bonded to three $\mathrm{C}$ atoms in a sp $\mathrm{s}^{2}$ configuration. The other is the pyridine-type doping, which $\mathrm{N}$ is bonded with two coordinated bondings. From the position of the $\mathrm{N}_{1 \mathrm{~s}}$ level, we can distinguish the $\mathrm{N}$-doping type. Fig. 2.11 is the highresolution XPS spectra of $\mathrm{N}_{1 \mathrm{~s}}$. From it we can see that the $\mathrm{N}_{1 \mathrm{~s}}$ core level lied at $399.59 \mathrm{eV}$ is in good agreement with the spectral feature of pyridine-type N-doping(Gammon et al., 2003). Furthermore, element analysis was used to reveal the precise $\mathrm{N}$ content of the $\mathrm{N}$-doped multi-layered graphene sheets. The result shows that the content of $\mathrm{N}$ is $\sim 1 \%$ for the sample produced in the atmosphere of pure $\mathrm{NH}_{3}$.
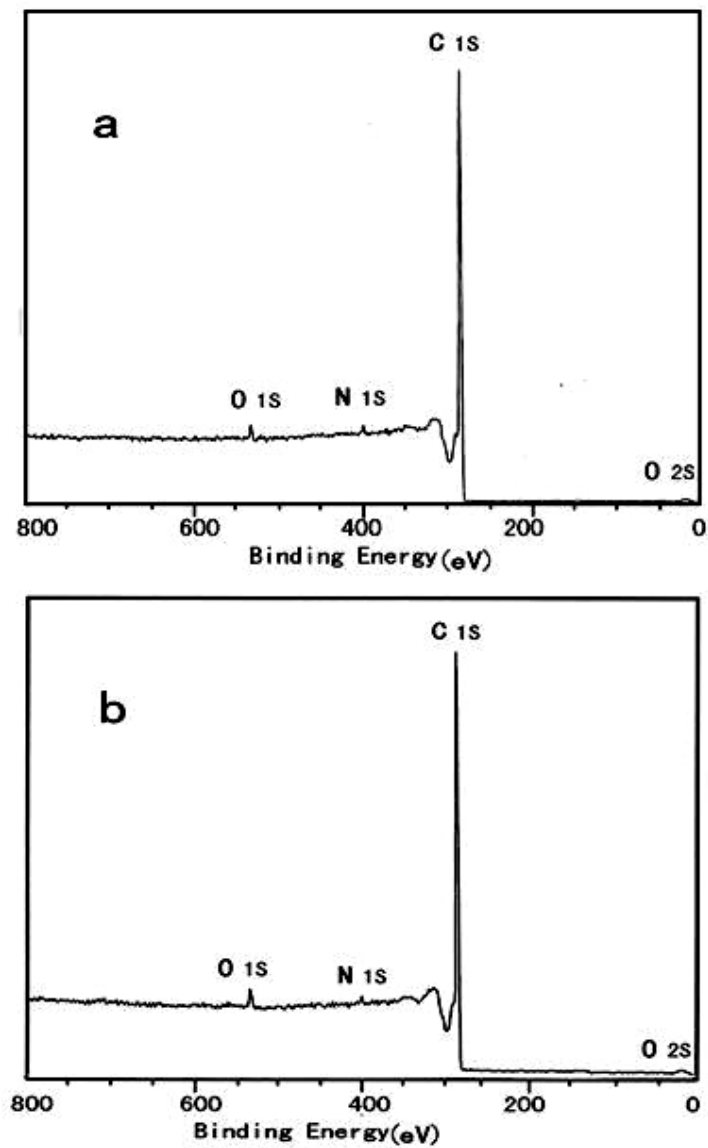

Fig. 2.10. XPS spectra of the two samples prepared in mixing atmosphere of $\mathrm{NH}_{3}$ and $\mathrm{He}$ with the different ratio of $\mathrm{NH}_{3} / \mathrm{He}$ (V/ V): (a) $\mathrm{NH}_{3}: \mathrm{He}=1: 1$; (b) $\mathrm{NH}_{3}: \mathrm{He}=1: 0$. (Li et al. 2010a. Reproduced by permission of Elsevier Limited) 


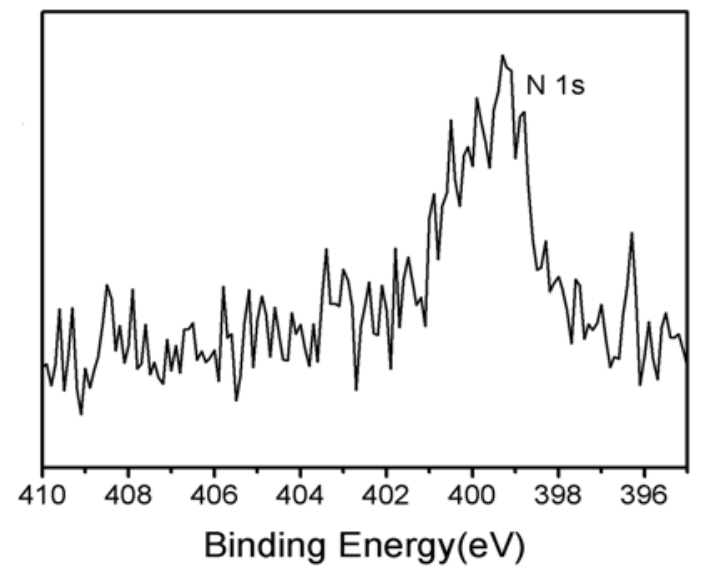

Fig. 2.11. High-resolution XPS spectra of $\mathrm{N}_{1 \mathrm{~s}}$. (Li et al. 2010a. Reproduced by permission of Elsevier Limited)

\subsubsection{Graphene synthesized in the atmosphere of air}

Wang et al.( 2010) synthesized graphene in the atmosphere of air. The yield of their products was found to be strongly dependent on the initial air pressure. Fig. 2.12 shows the TEM images of the products corresponding to differing initial air pressure. When the initial air pressure is 1000 torr, the product is dominated by graphene nanosheets, and there are also small amounts of carbon nanohorns (Fig. 2.12a). Carbon nanohorns are single-layered tubular structures with horn-shape tips, which are frequently observed near the edge of the graphene nanosheets (a carbon nanohorn is indicated with an arrow in Fig. 2.12a). When the initial air pressure is decreased to 700 torr, the amount of graphene nanosheets is reduced and there are more carbon nanohorns in the products (Fig. 2.12b). Further decreasing of the air pressure to 400 torr leads to the formation of carbon nanospheres together with nanohorns (Fig. 2.12c). The carbon nanohorns can be removed by oxidation in air. After heat-treatment in air, most of the carbon nanohorns are oxidized to gases and graphene nanosheets with a high purity is obtained (Fig. 2.12d).

Based on TEM analysis, the width of the graphene nanosheets is mainly in the range of $\sim 100-200 \mathrm{~nm}$. This size range is similar to that of graphene nanosheets produced by arc discharge in $\mathrm{H}_{2}$ (Subrahmanyam et al., 2009). The layer number of the graphene nanosheets produced in air atmosphere mainly ranges from 2 to 10 . Typical highresolution TEM images of graphene are shown in Fig. 2.13, in which the graphene layers of the nanosheets can be distinguished. Fig. 2.13a shows a graphene nanosheet with triple layers at the lower part and single layer at the upper part. The interlayer distance of the graphene nanosheets was determined to be $0.37-0.39 \mathrm{~nm}$, which is larger than that of bulk graphite $(0.34 \mathrm{~nm})$.

Fig. 2.14 depicts the Raman spectra of the raw and purified graphene nanosheets produced with an initial air pressure of 1000 torr. Three dominant peaks at 1325, 1570, and $2646 \mathrm{~cm}^{-1}$, known as the D band, $\mathrm{G}$ band and $2 \mathrm{D}$ band, are observed for the two samples. It is apparent that intensity ratio of $\mathrm{D}$ band to $\mathrm{G}$ band for the purified sample is significantly lower than that for the raw material. This difference is caused by the elimination of the carbon 

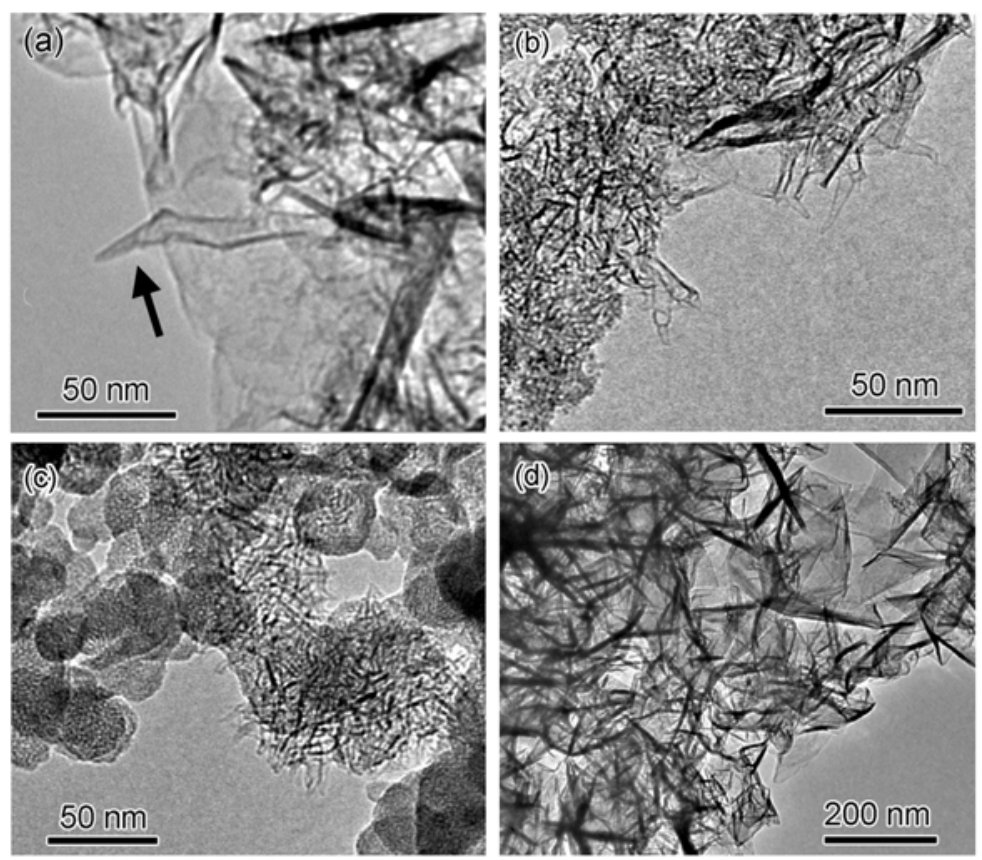

Fig. 2.12. (a-c) TEM images of the products for different initial air pressure of 1000, 700 and 400 torr, respectively. The arrow in (a) indicates the carbon nanohorn. (d) TEM image of products after oxidation in air. (Wang et al. 2010. Reproduced by permission of IOP Publishing Limited)
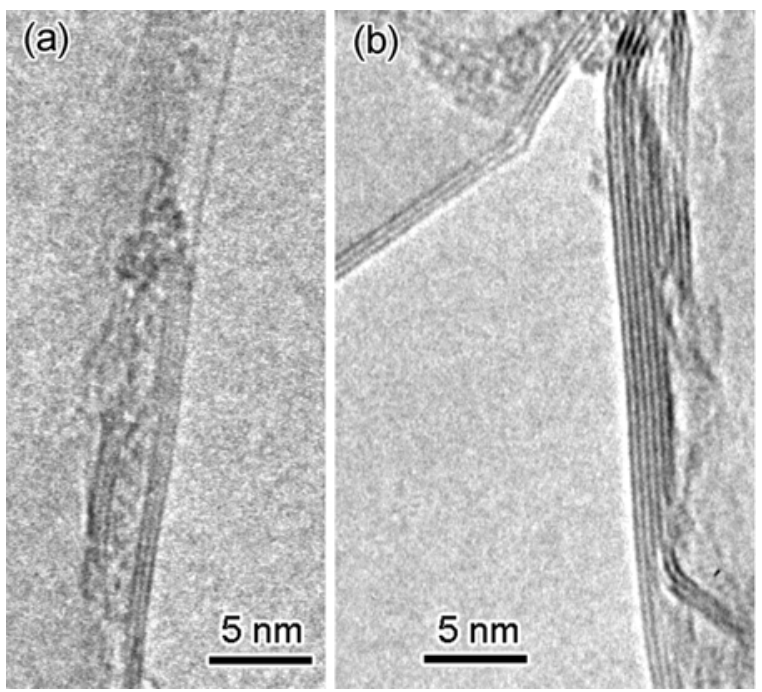

Fig. 2.13. (a, b) High-resolution TEM images of graphene nanosheets showing the edges of the graphene. (Wang et al. 2010. Reproduced by permission of IOP Publishing Limited) 
nanohorns. It is known that the $\mathrm{D}$ band is related to disorder of carbon materials and the $\mathrm{G}$ band corresponds to the zone center $\mathrm{E}_{2 \mathrm{~g}}$ mode. Because of the curvature and the coniform tips of the carbon nanohorns, the intensity of the D band for the carbon nanohorns is stronger than that for the flat graphene sheets. Therefore, the D band is depressed after the elimination of the carbon nanohorns. On the other hand, the position of the $2 \mathrm{D}$ band is associated with the thickness of the graphene sheets. The $2 \mathrm{D}$ band of graphite is located at $2685 \mathrm{~cm}^{-1}$, while the 2D band of graphene with few (less than five) layers is in the range of $\sim 2640-2680 \mathrm{~cm}^{-1}$ (with excitation wavelength of $633 \mathrm{~nm}$ ). Thus the frequency of $2 \mathrm{D}$ band for the purified sample in the present study $\left(2646 \mathrm{~cm}^{-1}\right)$ is a signature of few-layered graphene nanosheets.

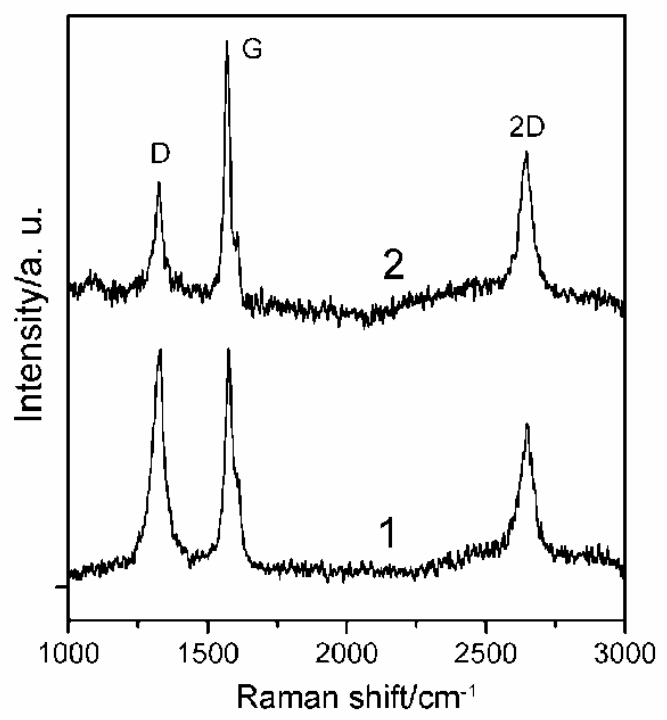

Fig. 2.14. Raman spectra of raw (curve 1) and purified (curve 2) graphene nanosheets. D, G and $2 \mathrm{D}$ bands are observed. (Wang et al. 2010. Reproduced by permission of IOP Publishing Limited)

\section{Formation mechanisms of graphene with arc-discharge method}

There are two formation mechanisms of graphene according to the atmosphere. In the atmosphere of $\mathrm{H}_{2}$, it makes use of the knowledge that the presence of $\mathrm{H}_{2}$ during the arc discharge process terminates the dangling carbon bonds with hydrogen and prevents the formation of closed structures(Wang et al., 1995). $\mathrm{H}_{2}$ plays a key role in the formation of graphene by preventing the rolling of sheets into nanotubes and graphitic polyhedral particles. In the mixing atmosphere of $\mathrm{NH}_{3}$ and $\mathrm{He}$, the formation mechanism is similar to the atmosphere of $\mathrm{H}_{2} . \mathrm{NH}_{3}$ not only acts as the nitrogen source, but also suppresses the formation of fullerenes. $\mathrm{NH}_{3}$ also plays another important role for the formation of $\mathrm{N}$-doped graphene besides the as-described function. It decomposes to nitrogen and hydrogen under the high temperature during discharge process. The highly reactive hydrogen terminates the dangling carbon bonds at the edge of graphene sheets thereby preventing the graphene 
sheets from closing(Maiti et al., 1995). At the same time, the high pressure of buffer gas and high current provide more energy to prompt the ionization of anode, which engenders bigger carbon clusters. This further guarantees the shape of graphene sheets(Kokai et al., 2004).

In the atmosphere of air, the pressure of the system is a critical factor that determinates the yield of graphene. As the graphene sheets are flat, the formation of graphene might be related to inhibition of the curvatures of graphene layers by high pressure of the system. The pressure-induced formation of graphene is different from the growth mechanism of graphene in $\mathrm{H}_{2}$ and $\mathrm{NH}_{3}$, when hydrogen atoms could terminate the dangling bonds on the edge of graphene sheets and thereby prevent their rolling into closed structures. The formation of graphene in $\mathrm{H}_{2}$ and $\mathrm{NH}_{3}$ is associated with the chemical activity of the atmosphere. On the contrary, pressure-induced formation of graphene is independent of the chemical activity of the buffer gas.

\section{Summary}

Graphene is an amazing new carbon nanomaterial, which possess distinct characteristics. The applications of graphene mainly focus on electronics, molecular gas sensors, and energy storage etc. To achieve these goals, the massive production of high quality graphene is the precondition. The production of graphene in decagram-scale with high purity has been achieved by the arc-discharge method. This has promoted further applications of graphene in many technological areas.

\section{Acknowledgements}

The work by the authors was supported by the National Natural Science Foundation of China (Nos. 20771010, 504371004 and 90206048) and the Ministry of Science and Technology of China (Grant 2006CB932701 and 2007AA03Z3110).

\section{References}

Ayala P, Grüneis A, Gemming T, Grimm D, Kramberger C, Rümmeli M H, Freive F L, Kuzmany H, Pfeiffer R, Barreiro A, Büchner B, Pichler T. (2007). Tailoring N-doped single and double wall carbon nanotubes from a mondiluted carbon/ nitrogen feed stock. I Phys. Chem. C, 111, 7, 2879-2884, ISSN.

Booth T J, Blake P, Rahul R N, Jiang D, Hill E W, Bangert U, Bleloch A, Gass M, Novoselov K S, Katsnelson M I, Geim A K. (2008). Macroscopic graphene membranes and their extraordinary stiffness. Nano Lett., 8, 8, 2442-2446, ISSN.

Chae S J, Günes F, Kim K K, Kim E S, Han G H, Kim S M, Shin H J, Yoon S M, Choi JY, Park M H, Yang C W, Pribat D, Lee Y H. (2009). Synthesis of large-area graphene layers on poly-nickel substrate by chemical vapor deposition: wrinkle formation. $A d v$. Mater., 21, 22, 2328-2333, ISSN.

Choucair M, Thordarson P, Stride JA. (2009). Gram-scale production of graphene based on solvthermal synthesis and sonication. Nat. Nanotechnol., 4,1, 30-33, ISSN.

Dervishi E, Li Z R, Watanabe F, Biswas A, Xu Y, Biris A R, Saini V, Biris A S. (2009). Largescale graphene production by RF-Ccvd method. Chem. Comm., 27, 4061-4063, ISSN. 
Du X S, Yu Z Z, Dasari A, Ma J, Mo M, Meng Y Z, Mai Y W. (2008). New methods to prepare graphite nanocomposites. Chem. Mater., 20, 6, 2066-2068, ISSN.

Emtsev K V, Bostwick A, Horn K, Jobst J, Kellogg G L, Ley L, McChesney J L, Ohta T, Reshanov SA, Röhrl J, Rotenberg E, Schmid A K, Waldmann D, Weber H B, Seyller T. (2009). Towards wafer-size graphene layers by atmospheric pressure graphitization of sllicon carbide. Nat. Mater., 8, 3, 203-207, ISSN

Fan X B, Peng W, Li X Y, Wang S, Zhang G L, Zhang F B. Deoxygenation (2008). of exfoliated graphite oxide under alkaline conditions: a green route to graphene preparation. Adv. Mater., 20, 23, 4490-4493, ISSN.

Ferrari A C, Meyer J C, Scardaci V, Casiraghi C, Lazzeri M, Mauri F. (2006). Raman spectrum of graphene and graphene layers. Phys. Rev. Lett., 97, 18, 187401, ISSN.

Gammon W J, Kraft O, Reilly A C, Holloway B C. (2003). Experimental comparison of N(1s) $\mathrm{X}$-ray photoelectron spectroscopy binding energies of hard and elastic amorphous carbon nitride films with reference organic compounds. Carbon, 41, 10, 1917-1923, ISSN.

Geim A K, Novoselov K S. (2007). The rise of graphene. Nat. Mater., 6, 3, 183-191, ISSN.

Juang Z Y, Wu C Y, Lo C W, Chen W Y, Huang C F, Hwang JC, Chen F R, Leou K C, Tsai C H. (2009). Synthesis of graphene on silicon carbide substrates at low temperature. Carbon, 47, 8, 2026-2031, ISSN.

Kastner J, Pichler T, Kuzmany H, Curran S, Blau W, Weldon D N, Delamesiere M, Draper S, Zandbergen H. (1994). Resonance Raman and infrared spectroscopy of carbon nanotubes. Chem. Phys. Lett., 221, 1-2, 53-58, ISSN.

Kokai F, Koshi A, Kasuya D, Hirahara K, Takahashi K, Nakayama A, Ishihara M, Koga Y, lijima S. (2004). Three nanostructured graphitic particles and their growth mechanisms from high-temperature carbon vapor confined by Ar gas. Carbon, 42, 12-13, 2515-2520, ISSN.

Krätschmer W, Lamb L D, Fostiropoulos K, Huffman D R. (1990). Solid C60: a new form of carbon. Nature, 347, 6291, 354-358, ISSN.

Li D, MÜller M B, Gilje S, Kaner R B, Wallace G G. (2008). Processable aqueous dispersions of graphene nanosheets. Nat. Nanotechnol., 3, 2, 101-105, ISSN.

Li X L, Wang X R, Zhang L, Lee S W, Dai H J. (2008). Chemically derived, ultra-smooth graphene nanoribbon semiconductors. Science, 319, 5876, 1229-1232, ISSN.

Li X S, Cai W W, An J, Kim S, Nah J, Yang D X, Piner R, Velamakanni A, Jung I, Tutuc E, Banerjee S K, Colombo L, Ruoff R S. (2009). Large-area synthesis of high-quality and uniform graphene films on copper foils. Science, 324, 5932, 1312-1314, ISSN.

Li N, Wang Z Y, Zhao K K, Shi Z J, Gu Z N, Xu S K. (2010a). Large scale synthesis of Ndoped multi-layered graphene sheets by simple arc-discharge method. Carbon, 48, 1, 255-259, ISSN.

Li N, Wang Z Y, Zhao K K, Shi Z J, Gu Z N, Xu S K. (2010b). Synthesis of single-wall carbon nanohorns by arc-discharge in air and their formation mechanism. Carbon, 48, 5, 1580-1585, ISSN.

Maiti A, Brabec C J, Roland C, Bernholc J. (1995). Theory of carbon nanotube growth. Phys. Rev. B, 52, 20, 14850-14858, ISSN.

Malesevic A, Vitchev R, Schouteden K, Volodin A, Zhang L, Tendeloo G V, Vanhulsel A, Haesendonck C V. (2008). Synthesis of few-layer graphene via microw ave plasmaenhanced chemical vapor deposition. Nanotechnology, 19, 30, 305604, ISSN. 
McAllister M J, Li JL, Adamson D H, Schniepp H C, Abdala A A, Liu J, Herrera-Alonso M, Milius D L, Car R, Prud'homme R K, Aksay I A. (2007). Single sheet functionalized graphene by oxidation and thermal expansion of graphite. Chem. Mater., 19, 18, 4396-4404, ISSN.

Niyogi S, Bekyarova E, Itkis M E, McWilliams J L, Hamon M A, Haddon R C. (2006). Solution properties of graphite and graphene. I Am. Chem. Soc., 128, 24, 7720-7721, ISSN.

Novolesov K S, Gleam A K, Morozov S V, Jiang D, Zhang Y, Dubonos S V, Grigorieva I V, Firsov A A. (2004). Electric field effect in atomically thin carbon films. Science, 306, 5296, 666-669, ISSN.

Parvizi F, Teweldebrhan D, Ghosh S, Calizo I, Balandin A A, Zhu H, Abbaschian R. (2008). Properties of graphene produced by the high pressure-high temperature growth process. Micro\& Nano Lett, 3, 1, 29-34, ISSN.

Reina A, Jia X, Ho J, Nezich D, Son H, Bulovic V, Dresselhaus M S, Kong J. (2009). Large area, few-layer graphene films on arbitary substrates by chemical vapor deposition. Nano Lett., 9, 1, 30-35, ISSN.

Subrahmanyam K S, Vivekchand S R C, Govindaraj A, Rao C N R. (2008). A study of graphemes prepared by different methods: characterization, properties and solubilization. el Mater. Chem., 18, 13, 1517-1523, ISSN.

Subrahmanyam K S, Panchakarla L S, Govindaraj A, Rao C N R. (2009). Simple method of preparing graphene flakes by an arc-discharge method. I Phys. Chem. C, 113, 11, 4257-4259, ISSN.

Wang X K, Lin X W, Dravid V P, Ketterson J B, Chang R P H. (1995). Carbon nanotubes synthesized in a hydrogen arc-discharge. Appl. Phys. Lett., 66, 18, 2430-2432, ISSN.

Wang X K, Lin X W, Mesleh M, Jarrold M F, Dravid V P, Ketterson JB, Chang R P H. (1995). The effect of hydrogen on the formation of carbon nanotubes and fullerenes. $C$ Mater. Res., 10, 8, 1977-1983, ISSN.

Wang Z Y, Li N, Shi Z J, Gu Z N. (2010). Low-cost and large-scale synthesis of graphene nanosheets by arc discharge in air. Nanotechnology, 21, 17, 175602, ISSN.

Xu J X, L X, Zhou X H, He X R, Shi Z J, Gu Z N. (2004). Synthesis, Isolation and spectroscopic Characterization of Ytterbium-Containing Metallofullerenes. Chem. Mater., 16, 15, 2959-2964, ISSN.

Xu J X, Wang Z Y, Shi Z J, Gu Z N. (2005). Synthesis, Isolation and Spectroscopic Characterization of Yb-containing High Metallofullerenes. Chem. Phys. Lett., 409, 46, 192-196, ISSN.

Yuan G D, Zhang W J, Yang Y, Tang Y B, Li Y Q, Wang JX, Meng X M, He Z B, Wu C M L, Bello I, Lee C S, Lee S T. (2009). Graphene sheets via microwave chemical vapor deposition. Chem. Phys. Lett., 467, 4-6, 361-364, ISSN.

Zhu C Z, Guo S J, Fang Y X, Dong S J. (2010). Reducing sugar: new functional molecules for the green synthesis of graphene nano sheets. ACS Nano, 4, 4, 2429-2437, ISSN. 


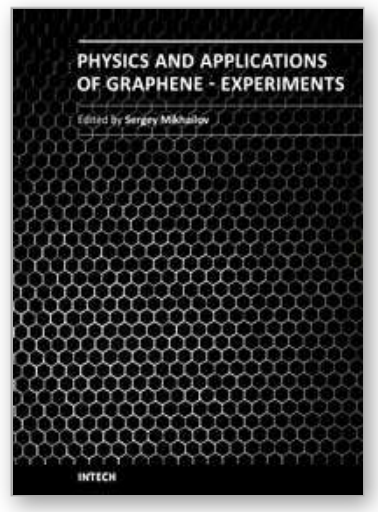

\author{
Physics and Applications of Graphene - Experiments \\ Edited by Dr. Sergey Mikhailov
}

ISBN 978-953-307-217-3

Hard cover, 540 pages

Publisher InTech

Published online 19, April, 2011

Published in print edition April, 2011

The Stone Age, the Bronze Age, the Iron Age... Every global epoch in the history of the mankind is characterized by materials used in it. In 2004 a new era in material science was opened: the era of graphene or, more generally, of two-dimensional materials. Graphene is the strongest and the most stretchable known material, it has the record thermal conductivity and the very high mobility of charge carriers. It demonstrates many interesting fundamental physical effects and promises a lot of applications, among which are conductive ink, terahertz transistors, ultrafast photodetectors and bendable touch screens. In 2010 Andre Geim and Konstantin Novoselov were awarded the Nobel Prize in Physics "for groundbreaking experiments regarding the two-dimensional material graphene". The two volumes Physics and Applications of Graphene - Experiments and Physics and Applications of Graphene - Theory contain a collection of research articles reporting on different aspects of experimental and theoretical studies of this new material.

\title{
How to reference
}

In order to correctly reference this scholarly work, feel free to copy and paste the following:

Nan Li, Zhiyong Wang and Zujin Shi (2011). Synthesis of Graphenes with Arc-Discharge Method, Physics and Applications of Graphene - Experiments, Dr. Sergey Mikhailov (Ed.), ISBN: 978-953-307-217-3, InTech, Available from: http://www.intechopen.com/books/physics-and-applications-of-grapheneexperiments/synthesis-of-graphenes-with-arc-discharge-method

\section{INTECH}

open science | open minds

\section{InTech Europe}

University Campus STeP Ri

Slavka Krautzeka 83/A

51000 Rijeka, Croatia

Phone: +385 (51) 770447

Fax: +385 (51) 686166

www.intechopen.com

\section{InTech China}

Unit 405, Office Block, Hotel Equatorial Shanghai

No.65, Yan An Road (West), Shanghai, 200040, China

中国上海市延安西路65号上海国际贵都大饭店办公楼 405 单元

Phone: +86-21-62489820

Fax: $+86-21-62489821$ 
(C) 2011 The Author(s). Licensee IntechOpen. This chapter is distributed under the terms of the Creative Commons Attribution-NonCommercialShareAlike-3.0 License, which permits use, distribution and reproduction for non-commercial purposes, provided the original is properly cited and derivative works building on this content are distributed under the same license. 